\title{
Erratum to: The Limits of Corporate Social Responsibility: Techniques of Neutralization, Stakeholder Management and Political CSR
}

\author{
Gary Fooks • Anna Gilmore · Jeff Collin • \\ Chris Holden · Kelley Lee
}

Published online: 21 June 2012

(C) Springer Science+Business Media B.V. 2012

\section{Erratum to: J Bus Ethics}

DOI 10.1007/s10551-012-1250-5

The authors of the above mentioned article have erroneously forgotten to change to first second sentence of the second paragraph of the introduction to:

Specifically, these studies suggest that BAT and Philip Morris use CSR politically to prevent the introduction of legally enforceable tobacco control measures which have a proven record of effectiveness in reducing tobacco consumption.

The last row of Table 1 'Techniques of neutralization as they apply to corporate actors' should read:

Corporate actor claims that shifts in public attitudes rather than their own behaviour explains public condemnation.

The online version of the original article can be found under doi:10.1007/s10551-012-1250-5.

G. Fooks $(\bowtie)$ - A. Gilmore

Department of Health, University of Bath, Claverton Down, Bath BA2 7AY, UK

e-mail: g.fooks@bath.ac.uk

A. Gilmore

e-mail: a.gilmore@bath.ac.uk

J. Collin

Global Health Policy, Centre for International Public Health

Policy, School of Health in Social Science, University

of Edinburgh, Medical Buildings, Teviot Place,

Edinburgh EH8 9AG, UK

e-mail: jeff.collin@ed.ac.uk

C. Holden

Social Policy and Social Work, University of York, Heslington,

York YO10 5DD, UK

e-mail: chris.holden@york.ac.uk

K. Lee

Faculty of Health Sciences, Simon Fraser University,

Room 11322, Blusson Hall, 8888 University Drive,

Burnaby, BC V5A 1S6, Canada

e-mail: kelley_lee@sfu.ca 